\title{
THREE-DIMENSIONAL CULTURES OF OSTEOGENIC AND CHONDROGENIC CELLS: A TISSUE ENGINEERING APPROACH TO MIMIC BONE AND CARTILAGE IN VITRO
}

\author{
Federico Tortelli and Ranieri Cancedda*
}

Dipartimento di Oncologia, Biologia e Genetica, Università di Genova, and Istituto Nazionale per la Ricerca sul Cancro, Genoa, 16132, Italy

\begin{abstract}
Capturing the complexity of bone and cartilage into three-dimensional in vitro models remains one of the most important challenges in the field of the tissue engineering. Indeed, the development and the optimization of novel culture systems may be necessary to face the next questions of bone and cartilage physiology. The models should faithfully mimic these tissues, resembling their organization, their mechanical properties and their physiological response to different stimuli. Here we review the recent advances in the field of the three-dimensional cultures of both osteogenic and chondrogenic cells. In particular, we highlight the most important studies that, to our knowledge, have investigated the response of the cells to the three-dimensional environment provided by the diverse types of scaffold.
\end{abstract}

Keywords: bone, cartilage, three-dimensional cultures, in vitro.

*Address for correspondence:

Ranieri Cancedda

Istituto Nazionale per la Ricerca sul Cancro,

Largo R. Benzi, 10

16132 Genova,-Italy

Telephone Number: +39-0105737398

FAX Number: +39-0105737257

E-mail: ranieri.cancedda@unige.it

\section{Introduction}

Monolayer culture has played a key role in the field of bone and cartilage physiology as well as in other fields of cellular biology. Osteogenic and chondrogenic cells have been extensively investigated using the traditional 2D culture systems and many researchers have employed monolayer cultures to investigate cellular differentiation and extracellular matrix (ECM) deposition. Although these traditional cultures can be still useful to investigate the molecular mechanisms regulating cell differentiation, it is now evident that this approach cannot be used to faithfully mimic bone and cartilage. Indeed, the complex organization between cells and ECM is strictly dependent on the three-dimensional environment in which they are organized.

Tissue engineering is the process of creating functional three-dimensional tissues using cells combined with scaffolds or devices that facilitate cell growth, organization and differentiation. The development of models based on the integration between cells and biomaterials could help us to better understand the basic mechanisms of bone and cartilage physiology. The models should faithfully mimic these tissues; resemble their organization, their mechanical properties and their physiological response to different stimuli. Bone is a complex hard and elastic tissue where living cells are embedded in a mineralized organic matrix composed mostly of hydroxyapatite and Type I collagen. In this tissue, the main cellular players (osteoblasts, osteoclasts and endothelial cells) are in close contact with the mineralized matrix and well organized within. As in bone, the interaction between ECM and cells in cartilage is a key factor to maintain the health of native cartilage tissue where chondrocytes are buried in an extracellular matrix composed of collagen fibres, proteoglycans, glycosaminoglycans, glycoproteins and elastin. The importance of the ECM in the tissue organization led to the development of a large number of different types of scaffold such as natural polymeric materials, synthetic polymers and ceramics. Many researchers have developed different in vitro and in vivo models of bone and cartilage by using these biomaterials in association with different cells. However, most of these studies aimed at the resolution of clinical problems and thus, were mainly interested in the development of in vivo animal models. On the contrary this review highlights the most relevant and promising studies where three-dimensional culture systems have been developed. The response of the cells to the different environments provided by the diverse scaffolds is also extensively discussed. 
(A)

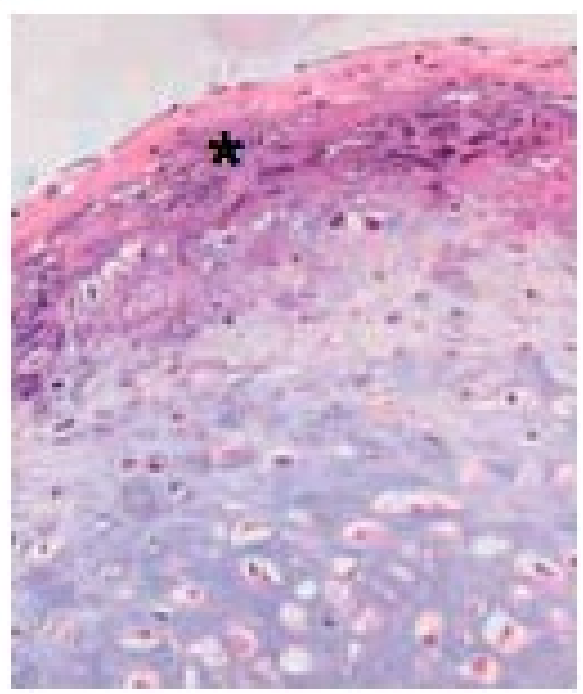

(B)

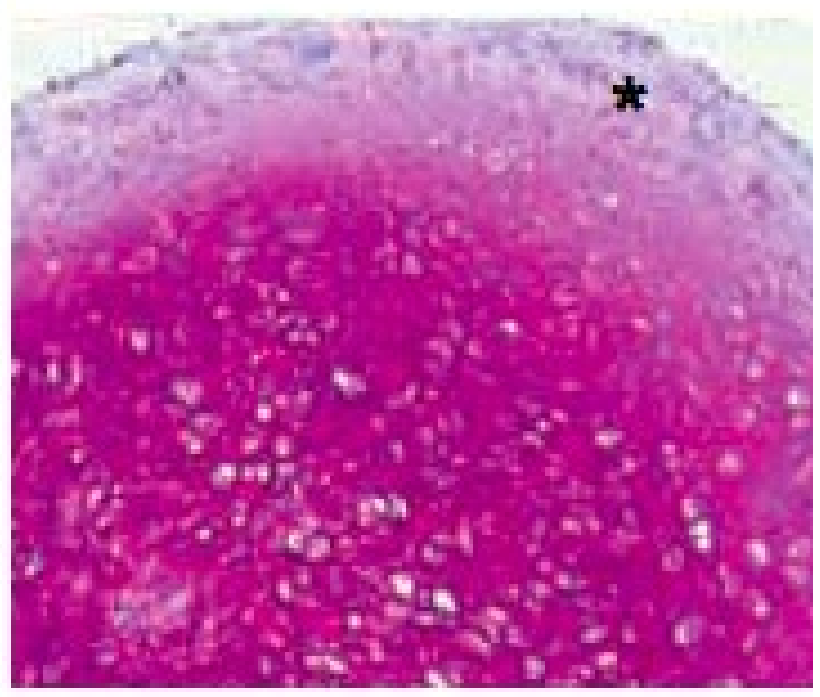

Figure 1: Chondro-osseus organoid, bone collar is highlighted by black asterisks. (A) Haematoxilin/eosin staining (B) Toluidine Blue staining. Reproduced from Muraglia et al. (2003).

\section{Three-dimensional cultures to mimic bone in vitro}

The development of an in vitro model of bone should help us to study the physiology of this complex tissue and, at the same time, to test new drugs acting on bone metabolism and turnover, thus limiting the use of animal models and the costs of these types of studies. An ideal bone model should summarize the main features of the native bone, such as the peculiar mechanical and physical properties of the tissue, and should contain the cellular types involved in the maintenance of bone health. To achieve this ambitious goal, several studies have been performed using various scaffolds and different cell types (osteoblasts, osteoclasts and endothelial cells).

\section{Culturing osteogenic cells in micro-mass culture systems}

The less complex three-dimensional culture system is the micro-mass culture, based on the establishment of 3D cultures supported uniquely by the ECM produced by a pellet of cultured cells.

The use of micro-mass cultures as a potential way to investigate osteogenic cell differentiation has been tested in several studies. It has been demonstrated that the micro-mass culture condition affects the expression of osteogenesis-related genes. In fact, 3D micro-mass cultures of human osteoblasts showed expression of alkaline phosphatase (ALP), bone sialoprotein (BSP), type I collagen, osteonectin $(\mathrm{ON})$ and osteopontin $(\mathrm{OPN})$ throughout the culture. The expression of osteocalcin (OC) was restricted to the longest culture time (48 days). Moreover, deposition of calcium was also documented, even if a highly organized structure similar to bone ECM was not observed (Ferrera et al., 2002).

Interestingly, mineralization was also reported in cartilage "beads" resulting from the cultures of mesenchymal stem cells (MSCs) under micro-mass condition and stimulated with an osteo-inductive medium. This pellet culture system led to the formation of a chondro-osseus organoid in which a bony collar was reported around hyaline cartilage formed in the centre of the pellet (Fig. 1) (Muraglia et al., 2003). Taken together, these results suggest that human osteogenic cells cultured in $3 \mathrm{D}$ micro-mass conditions are able to fully differentiate up to mineral deposition even if the system does not faithfully mimic bone tissue. Moreover, the use of this culture system does not allow high-throughput cultures and this represents a strong limitation for its use as model of bone for drug tests. Recently, a scaffold-free 3D microfluidic cell culture system (3D- $\mu$ FCCS) has been developed (Ong et al., 2008). In this model, the cells were chemically modified with an inter-cellular linker (polyethyleneimine-hydrazide) and introduced into the microfluidic channels; the inter-cellular linker induced the formation of 3D multicellular aggregates that were subsequently cultured under perfusion. The use of polyethyleneimine-hydrazide to effect 3D cell culture facilitates the establishment of a more natural extracellular matrix environment. Indeed, the inter-cellular linker is transient (half-life of 2 days), thus allowing cells to secrete and remodel their extracellular matrix environment (Ong et al., 2007). MSCs cultured for 1 week in 3D- $\mu$ FCCS showed good cell viability, preserved 3D cell morphology and were able to produce a mineralized matrix as in the 2D counterpart. In our opinion, although the use of 3D microfluidic cell culture systems is a promising tool for biological research and drug screening applications, further investigations are needed to verify its potential in long-term cultures.

\section{Synthetic-based polymers as a scaffold for cultures of osteogenic cells}

Synthetic polymers can be produced under controlled conditions and therefore exhibit predictable and reproducible mechanical and physical properties such as tensile strength, elastic modulus and degradation rate (Lutolf and Hubbell, 2005; Rezwan et al., 2006). Moreover, three-dimensional biodegradable synthetic polymeric systems are of particular 
interest because their porosity, hydrophilicity and degradation time can be varied, and they can be manufactured with a high degree of reproducibility (Godbey and Atala, 2002; Lutolf and Hubbell, 2005).

Commonly used biodegradable synthetic polymers for $3 \mathrm{D}$ scaffolds in bone tissue engineering are saturated poly- $\alpha$-hydroxy esters, including poly(lactic acid) (PLA), poly(glycolic acid) (PGA), poly( $\varepsilon$-caprolactone), as well as poly(lactic-coglycolide) (PLGA) copolymers (Alvarez-Barreto et al., 2007; Cuddihy and Kotov, 2008; Freed et al., 1994; Goh and Ooi, 2008; Hutmacher, 2000; Leung et al., 2008; Middleton and Tipton, 2000; Tsuji, 2005; Wang S et al., 2005). Cellular adhesion to PLGA is significantly higher than on PLA surfaces. Indeed, human osteoblasts grown on PLGA produced higher levels of ECM molecules and developed a more advanced cytoskeleton than was observed on PLA (El-Amin et al., 2003). Moreover, PLGA scaffolds supported rat osteoblast proliferation and differentiation, as suggested by the increase of ALP activity and mineral deposition after 56 days of culture (Ishaug et al., 1997; Ishaug-Riley et al., 1998). However, the deposition of ECM morphologically identical to bone tissue was far from being reached and further investigations are needed to optimize the model. In this context, dynamic flow could help to achieve better results. Indeed, several studies have shown that dynamic flow positively affected cell distribution through the scaffolds and further enhanced cell phenotypic expression and mineralized matrix synthesis within PLGA constructs compared to the static condition counterpart (Goldstein et al., 2001; Goldstein et al., 1999; Stiehler et al., 2009; Yu et al., 2004). However, the short time of the cultures (maximum 14 days) did not allow the deposition of a highly-organized bone-like matrix and thus, in our opinion, longer cultures are necessary to evaluate better the potential of these scaffolds.

Poly( $\varepsilon$-caprolactone) has a good biocompatibility and processability but its high hydrophobicity and low degradability in vivo make it less suitable for long term applications (Sung et al., 2004). Several studies, however, indicated this polymer as a promising material to develop a three-dimensional in vitro model of bone (Ciapetti et al., 2003; Guarino et al., 2008; Li et al., 2005; Porter et al., 2009). Although the in vitro deposition of an highly-organized extracellular matrix similar to native bone in these scaffolds has not been yet obtained, PLA fibers reinforced with poly( $\varepsilon$-caprolactone) allowed a high proliferation of human MSCs and human osteoblasts, as well as the expression of ALP. However, the ALP expression after 5 weeks of culture in PLA fibres reinforced with poly( $\varepsilon$-caprolactone) scaffolds was lower with respect to the control cultures performed in traditional tissue culture dishes. This indicates, in our opinion, a negative effect on MSC differentiation and osteoblast maturation (Guarino et al., 2008). In contrast, poly( $\varepsilon$-caprolactone) nanowire scaffolds induced rat MSC differentiation compared to smooth poly(e-caprolactone) scaffolds after only 3 weeks of culture, thus indicating an important role of the micro- and nanoscale structure of the scaffold. Indeed, an increase of ALP, OC and OPN expression was observed, as well as a good mineralization of the nanowire scaffolds (Porter et al., 2009). However, an appropriate histological analysis was lacking and further investigations are needed to evaluate the morphology of the newly-formed tissue and to investigate the effect of the nanowire microenvironment on human cell differentiation.

To improve the biological functionality of the synthetic polymers, composite scaffolds were developed using hydroxyapatite, biphase calcium phosphate or tricalcium phosphate. Many in vitro studies have demonstrated that composite scaffolds support attachment, proliferation and differentiation of MSCs (Causa et al., 2006; Charles-Harris et al., 2008; Chen et al., 2008; Jung et al., 2005; Verrier et al., 2004; Yao et al., 2005). Poly(DL-lactic acid), (PDLLA)/Bioglass ${ }^{\odot}$, PLA/calcium metaphosphate and PLGA/ bioactive glass composites scaffolds have been developed and in vitro tested. Although an increase of cell adhesion has been showed, the effects of these scaffolds on in vitro cell differentiation should be better investigated (Jung et al., 2005; Verrier et al., 2004; Yao et al., 2005). Indeed, the increase of ALP activity in rat MSCs cultured on PLGA/bioactive glass is not sufficient to demonstrate a positive effect on cell differentiation and further studies are necessary to evaluate the expression of other key genes of osteogenesis such as osteocalcin, type I collagen, BSP and osteopontin (Yao et al., 2005). In this context, a recent paper has confirmed the necessity of further investigations on human MSC differentiation cultured on a different type of composite scaffold. Ko and colleagues showed that although nanofibrous scaffolds fabricated from the mixture of PLA and nanocrystal demineralized bone powders supported bone formation after 12 weeks of implantation, a positive effect on in vitro MSC differentiation compared to the PLA scaffolds counterpart was not observed. Indeed, after 14 days of culture, the expression levels of type I collagen, ALP and Runx2 were similar in both types of scaffolds, thus indicating the absence of MSC differentiation enhancement in the composite scaffold (Ko et al., 2008).

\section{Mimicking bone in vitro in collagen scaffolds}

The importance of type I collagen in bone ECM and its role in the developmental cascade leading to new bone from progenitor cells implicates this molecule as a candidate material for a biomimetic approach to bone tissue engineering scaffold design. It can be used intact or after proteolytic removal of the small nonhelical telopeptides, which reduces possible antigenicity. Further, there are two forms for native collagen, as swollen hydrogels or as sparse fibres in a lattice-like organization (Glowacki and Mizuno, 2008). Bovine type I collagen has been established as a promising biomaterial forming the basis of several commercial products such as CollapatII ${ }^{\odot}$ (Biomet Inc.), Healos $^{\odot}$ (Depoy Spine Inc.), Collagraft ${ }^{\odot}$ (Nuecoll Inc., Zimmer Inc.) and Biostite (Vebas S.r.l.) (Wahl and Czernuszka, 2006). A number of studies have been developed to optimize in vitro culture systems based on collagen scaffolds. The majority of the studies have focused on testing the biocompatibility of this natural polymer and on investigating both the proliferation and the differentiation of osteogenic cells in the three-dimensional environment provided by collagen sponges.

An increase of proliferation in human Sarcoma Saos-2 cells was observed when these cells were cultured under 
static conditions on a collagen scaffold. Moreover, the cells were able to colonize the collagen sponges and to synthesize osteocalcin in the three-dimensional network provided by the scaffold (Masi et al., 1992). Similar results have been obtained using the clonal osteogenic cell line MC3T3-E1 (Casser-Bette et al., 1990). Further increases in proliferation and differentiation were observed in a culture system based on murine K8 osteosarcoma cells cultured on collagen sponges under perfusion. The histological evaluation revealed greater viability, more ALP-positive cells and mineralization compared to the static counterpart. Moreover, Northern hybridization analysis showed an increase of both type I collagen and OC expression after 21 days of culture (Mueller et al., 1999). The known drawback of collagen sponges as scaffolds for cell proliferation and differentiation is their poor mechanical strength. To overcome the inherent weakness of collagen sponges, combination with other materials has been attempted. The incorporation of poly(glycolyc acid) (PGA) fibres enabled collagen sponges to increase resistance to compression in vitro and in vivo (Hiraoka et al., 2003). In vitro culture experiments revealed that the number of rat MSCs attached to the scaffolds increased with the incorporation of PGA fibres (Hosseinkhani et al., 2005). Moreover, the proliferation and the differentiation of MSCs cultured on PGA-reinforced collagen sponges were greatly influenced by culture conditions. Indeed, appropriate perfusion conditions enabled MSCs to improve the extent of proliferation and differentiation (Hosseinkhani et al., 2005).

The presence of hydroxyapatite (HA) crystals within the collagen network in bone ECM has prompted the development of several scaffolds based on this structure. The generation of scaffolds resembling the nature of bone matrix based on collagen and HA should offer a useful platform to assess cultures of osteogenic cells. Human MSCs seeded in collagen sponges reinforced with HA (ColHA scaffolds) and cultured for 28 days in both basal and osteogenic conditions revealed the penetration of ALP positive cells throughout the constructs as well as the synthesis of new matrix (Dawson et al., 2008). Immunohistochemical analysis revealed that osteocalcin was localized only in the periphery of the constructs, thus suggesting a limited diffusion of nutrient factors that does not allow for the formation of ECM in the centre of the scaffolds. As in other three-dimensional culture systems, the need of an appropriate perfusion of nutrient factors through the scaffolds is evident, thus suggesting that an adequate perfusion of medium is required. Moreover, although the ECM positively stained for both osteocalcin and type I collagen, the structure and the organization of the in vitro formed tissue was still far from that of native bone tissue.

Mineralized type I collagen-based scaffolds have been also used to support human osteoclast-like cells and osteoblast cells in a co-culture system. Interestingly, the osteoclast-like cells were able to invade and to degrade the scaffolds while osteoblasts proliferated, differentiated and produced mineralized ECM (Domaschke et al., 2006). All together, these results confirmed the potential of these types of scaffolds in mimicking bone tissue, although further investigations are still needed to optimize the cultures and to really have a homogeneous bone tissue growth and organization throughout the scaffold.

Culturing osteogenic cells in titanium based scaffolds

Titanium is a traditional inert biomaterial commonly used for implants that elicit a minimal immune response. It has been extensively employed as a fibre mesh based scaffold for three-dimensional culture in various studies focused on investigating the effect of medium perfusion on cell differentiation. Indeed, as reported in the literature, rat MSCs cultured on titanium fibre meshes under dynamic conditions increased their proliferation, differentiation and mineralized matrix production (Bancroft et al., 2002; van den Dolder et al., 2003). In this context, the fluid shear stress plays an important role. In fact, an increase in the perfused medium viscosity, coupled with a constant flow rate, led to an enhancement of the rate of mineral deposition (Sikavitsas et al., 2003). Moreover, along with fluid shear stresses, the bone like-ECM deposited in titanium fibre mesh scaffolds synergistically enhanced MSC differentiation. In fact, MSCs grown on decellularized scaffolds with a preexisting ECM exhibited greater cell numbers and increased calcium deposition (Datta et al., 2005; Datta et al., 2006; Pham et al., 2008).

The need to improve implant performance has led to the development of new biomaterials named organoapatites (OA) that are composed of hydroxyapatite (HA) and organic macromolecules (Stupp and Ciegler, 1992; Stupp et al., 1993a; Stupp et al., 1993b). A stable OA coating can be formed on titanium substrates and is able to promote both adhesion and proliferation of osteoblastic cells in vitro (Spoerke and Stupp, 2003). Zinc, an important trace element found in bone, is known to increase in vitro biomineralization (Yamaguchi et al., 1987). Zinc-containing hydroxyapatite ( $\mathrm{ZnOA}$ ) has been developed and in vitro studies have been performed. Osteoblastic cells MC3T3-E1 seeded on titanium-ZnOA scaffolds and cultured in a rotating bioreactor showed an increase of differentiation compared to the titanium scaffold counterpart, as reported by the increase of the collagen I expression and ALP activity (Storrie and Stupp, 2005). In our opinion, these results suggest that, although titanium scaffolds are promising candidates to monitor the gene expression modulation involved in osteogenesis, the extreme difficulty of performing histological evaluations of the constructs remains a big drawback that seems to be difficult to solve and can only in part be overcome with different techniques, such as confocal laser and scanning electron microscopy.

\section{Culturing osteogenic cells in bioceramic based scaffolds}

Although both hydroxyapatite- and beta-tricalcium phosphate-based scaffolds are widely used as constructs for bone tissue engineering, several different bioceramics have been developed in order to obtain an ideal scaffold for bone tissue engineering (Epinette and Manley, 2007; Marcacci et al., 2007; Mastrogiacomo et al., 2007; Uemura et al., 2003). Bioceramics are commonly considered the most promising biomaterials in this field. However, at the present time further investigations are still needed to obtain 
scaffolds with optimal biocompatibility, biodegradibility, osteoconductibility and with mechanical properties close to the native bone (Barrere et al., 2006; Mastrogiacomo et al., 2006a; Mastrogiacomo et al., 2006b; Pietak et al., 2007). Although is not difficult to obtain bone from implanted bioceramics combined with osteogenic cells (Dong et al., 2002; Lee et al., 2001; Muraglia et al., 1998; Quarto et al., 2001; Yoshikawa et al., 1996), the development of three-dimensional in vitro models of bone using bioceramics remains an important challenge that is still to be overcome. To our knowledge, the majority of the studies have been focused on solving the difficulties of homogeneously supplying oxygen and nutrients to cells within a large scaffold and to increase seeding efficacy, two of the biggest problems in bone tissue engineering. In order to improve bone deposition in vivo, many studies focused on the development of three-dimensional culture systems that should allow the culture of implantable constructs for tissue engineering purposes (Castano-Izquierdo et al., 2007; Timmins et al., 2007; Wendt et al., 2009). Unfortunately, adequate studies about the effects of the three-dimensional mineralized environment provided by the bioceramic-based scaffolds on cell differentiation in an in vitro environment were not performed. However, several studies pointed to the key aspects to be considered for the creation of functional bone models using bioceramics. The medium perfusion through the scaffolds seems to be an absolute requirement. Indeed, it was also demonstrated that low-pressure and oscillatory cell seeding led to an increased seeding efficiency, ALP activity and to a more homogeneous cell proliferation throughout the ceramic scaffolds (Du et al., 2008; Wang J et al., 2006). An increase in ALP activity and osteopontin secretion was also observed in rat MSCs cultured in a flow perfusion bioreactor, thus confirming the advantage of using bioreactors to culture cells within three-dimensional bioceramic scaffolds. The second key factor to take into account is the effect of both porosity and surface microstructure on the bioceramics' osteoinductive properties (Jones et al., 2009; Karageorgiou and Kaplan, 2005). Indeed, it has been suggested that not only chemistry but also geometry of the biomaterial in contact with the cells is a critical factor (Fujibayashi et al., 2004; Li et al., 2008). An increased surface area could concentrate more proteins, which may influence the attachment, proliferation and differentiation of cells within microstructured materials (Li et al., 2008).

Material opacity limits the downstream analysis of these in vitro models and thus represents an important drawback of bioceramics. Although the histological analysis of the scaffolds partially overcomes this issue, the development of transparent hydroxyapatites could be very useful for investigations in which fluorescence analyses are performed. Two-dimensional films of transparent hydroxyapatite (tHA) that were made by the spark plasma sintering process have been developed and used as substrate to culture rat MSCs up to 14 days (Kotobuki et al., 2005). Attachment, proliferation and osteogenic differentiation observed by light microscopy were similar to those obtained on tissue culture polystyrene dishes.

\section{Three-dimensional cultures to mimic cartilage in vitro}

The design of an ideal model of cartilage is still a hard challenge in the field of tissue engineering. Indeed, cartilage is a complex tissue capable of withstanding large compressive loads during everyday activities. Capturing these mechanical properties by coupling cells and scaffolds is one the most difficult tasks on the road to developing an in vitro model of cartilage. This model should permit cell proliferation and chondrogenic differentiation, as well as the retention of the newly-formed extracellular matrix within the scaffold, thus leading to a tissue that faithfully recreates cartilage morphology and properties.

\section{Chondrogenesis in micromass culture systems}

In 1998, Johnstone et al. published the development of an in vitro model of cartilage based on micro-mass culture. Rabbit MSCs were cultured in tubes and allowed to form three-dimensional aggregates in a chemically defined medium. This type of culture led to the generation of 3D structures that are directly reminiscent of true hyaline cartilage. The collagen types IIA, IIB and X have been detected in the cultures, thus confirming that chondrocytes were fully differentiated at the hypertrophic stage (Johnstone et al., 1998).

Other studies showed that the same system could be used to culture human MSCs in order to investigate the molecular mechanisms regulating chondrogenesis, thus validating the importance of the model (Mackay et al., 1998; Mastrogiacomo et al., 2001; Sekiya et al., 2001; Sekiya et al., 2002). Unfortunately, this model does not completely solve the problem of developing an in vitro model of cartilage. Indeed, the micromass culture system has several inherent disadvantages, namely, the small pellet size and the uniformly weak mechanical properties. Moreover, albeit never specifically addressed in literature, the necrotic areas found in the centre of larger micro-mass cultures bring to the light the need of a perfusion system in order to improve nutrient delivery within micro-mass cultures as well as the necessity to develop a model based on larger scaffolds with appropriate mechanical properties.

\section{Synthetic-based polymers as a scaffold for culture of chondrogenic cells}

For years, biomedical segmented polyurethanes have extensively been used in various implanted devices. Biodegradable polyurethane constructs seeded with articular chondrocytes supported cell attachment and the synthesis of cartilage-specific ECM proteins (Grad et al., 2003). The great advantage of the polyurethane scaffolds for cartilage tissue engineering is their mechanical properties that allow the application of mechanical stimulation. The importance of mechanical stimulation in developing cartilage models has been confirmed by applying a dynamic compression to the scaffolds; this treatment led to an increase of proteoglycan and Type II collagen expression, thus suggesting its active role in maintaining the chondrocytic phenotype (Wernike et al., 2008). A further increase of these chondrogenic markers was observed coupling a dynamic compression with a low oxygen tension in the 
medium (Wernike et al., 2008). Thus, these results further confirmed the importance of the combination between mechanical stimulation and low oxygen tension as a tool for modulating chondrocyte phenotype in order to obtain a cartilage-like tissue.

In order to optimize the proteoglycan retention and therefore to avoid their loss into the culture medium, a scaffold based on the combination of polyurethane and fibrin hydrogel has been developed and tested in vitro. The addition of fibrin to the polyurethane scaffold increased the percentage of the glycosaminoglycan (GAG) retained in the constructs and enhanced the expression of collagen II and aggrecan (Lee et al., 2005). However, the application of a mechanical compression doubled the rate of GAG release, thus suggesting that an optimization of the system to further improve the cartilage model based on polyurethane-fibrin scaffolds is still necessary.

Other scaffolds based on synthetic polymers as PGA, PLGA and PLA have been tested to verify their in vitro chondroinductive potential. Zwingmann and colleagues reported that although the adhesion of chondrocytes to PGA and PLGA scaffolds was similar, an increase of chondrogenic differentiation in PGA constructs was observed after 7 days of culture as showed by Type II collagen and aggrecan (Zwingmann et al., 2007). However, a tissue with morphology similar to cartilage was obtained only when the scaffolds were implanted, thus suggesting the need of long-term culture investigations.

As with PLGA scaffolds, PLA constructs supported chondrocyte proliferation and differentiation. Indeed, bovine chondrocytes cultured for 22 days on PLA scaffolds in a concentric cylinder bioreactor under low oxygen tension enhanced the ECM production leading to constructs in which an immature cartilage-like tissue was present (Saini and Wick, 2004).

Recently, Jung and colleagues developed an elastic biodegradable poly(L-lactide-co- $\varepsilon$-caprolactone) (PLCL) three-dimensional scaffold and tested it in several cartilage regeneration models (Jung et al., 2008). Although the work mostly considered in vivo investigations, several in vitro tests were also performed. Cell proliferation and in vitro differentiation were similar in PLCL scaffolds and in PLA control scaffolds throughout the culture period (up to 40 days), thus indicating that in static conditions and with no mechanical stimulation, the PLCL scaffolds did not exhibit chondroinductive properties in vitro. However, when implanted, the same scaffolds enhanced cartilage regeneration, thus suggesting the capacity of the PLCL scaffolds to deliver the mechanical signals of the surrounding biological environment to the adherent chondrocytes. In our opinion, these results indicate that scaffolds with a high in vivo cartilage regeneration performance may not be enough to promote in vitro chondrocyte differentiation and that, in addition, the correct combination of growth factors and active cells and/or molecules as those locally present in vivo may be required to obtain a proper stimulating environment.

Poly( $\varepsilon$-caprolactone) was used to develop both nanofibrous and porous scaffolds suitable for in vitro cultures. Moreover, these scaffolds can be used to test the effect of mechanical stimuli on chondrogenic cells. Indeed, several studies showed that different types of mechanical stimulation led to an enhancement of chondrogenic differentiation by cells cultured on these constructs (Jung et al., 2008; Li et al., 2003; Nam et al., 2008; Xie et al., 2007).

These results confirm that synthetic polymer based scaffolds are promising constructs for in vitro cartilage formation even if an optimization of the culture parameters (i.e., oxygen tension and mechanical stimulation) is necessary to develop long-term cartilage constructs. The main drawbacks of synthetic polymer scaffolds are the relatively low cell-seeding efficacy (which can partly be overcome by developing dynamic cell seeding systems) and the poor retention of the cartilage-like ECM secreted by the seeded cells. On the contrary, hydrogels ensure a homogeneous distribution of the cells suspended during the gelation process and retain the newly deposited ECM within the scaffolds. Considering the characteristics of both types of scaffold, the combination of hydrogels and synthetic polymers could overcome the above problems. Poly(caprolactone)-based polyurethane scaffolds/fibrin gels, alginate/PGA and Type I collagen/PGA constructs have recently been evaluated as culture substrates for bovine chondrocyte and rabbit MSC cultures (Eyrich et al., 2007; Hannouche et al., 2007). Chondrogenic cells seeded on these composite scaffolds were homogeneously distributed and retained a greater amount of glycosaminoglycans compared to control scaffolds (i.e., synthetic polymers or hydrogels alone) after 6 weeks of dynamic culture. Interestingly, rabbit MSCs cultured onto both Type I collagen/ PGA and PGA alone scaffolds organized an extracellular matrix similar to hyaline cartilage while cell proliferation and differentiation were both delayed when cells were suspended within an alginate gel, thus indicating that the activation of the chondrogenesis in MSCs seeded in 3D hydrogels was very much dependent upon the hydrogel nature (Hannouche et al., 2007). Further investigations are still needed to fully understand the role played in chondrogenesis by the different hydrogels and synthetic polymers.

\section{Culturing chondrogenic cells in naturally-derived hydrogels}

Hydrogels are three-dimensional, hydrophilic, polymeric networks capable of imbibing large amounts of water or biological fluids commonly used to mimic the chondrogenic environment. There are two main classes of hydrogels: i) naturally derived hydrogels, such as collagen and alginate and ii) synthetic-based hydrogels (Drury and Mooney, 2003). A recent review of Nicodemus and colleagues describes important considerations for designing biodegradable hydrogels for cell encapsulation (Nicodemus and Bryant, 2008); here we highlight only the most important studies that were focalized on mimicking cartilage in vitro.

It is known that in monolayer cultures chondrocytes dedifferentiate to a less specialized phenotype and produce less cartilage ECM. In contrast, the cells grown in 3D collagen constructs presented a prolonged chondrocyte specific gene expression and cartilage ECM synthesis during the time of culture (Glowacki and Mizuno, 2008).

Grodzinski and colleagues have shown that physiological levels of dynamic compression in cartilage strongly influ- 
enced the deposition patterns of cell-secreted proteoglycans (Quinn et al., 1998). In 2002, similar results have been obtained using an in vitro model based on Type I collagen scaffolds. Indeed, in bovine articular chondrocytes grown in collagen sponges to which hydrostatic fluid pressure (HFP) was applied, an enhancement of the synthesis of cartilage-specific matrix components has been reported (Mizuno et al., 2002).

In contrast to the need of an adequate perfusion of the medium through collagen sponges cultured to mimic bone tissue, perfusion conditions inhibit chondrogenesis by articular chondrocytes in the same scaffolds. This is in line with the physiology of the cartilage tissue where an environment with low oxygen tension enhances MSC differentiation into chondrocytes (Robins et al., 2005). These results emphasize the necessity of developing culture models where the oxygen tension and the mechanical forces must be optimized in order to obtain a fully functional cartilage.

Collagen scaffolds also represent promising constructs to maintain functional human disc cells as demonstrated by their high proliferation rate and their rate of proteoglycan synthesis in this type of matrix (Gruber et al., 2006). Nevertheless, it has been reported the proteoglycan content of similar scaffolds cultured up to 60 days never exceeded the $10 \%$ of that present in the mature nucleus pulposus. Moreover, in these experiments, more proteoglycans were lost in the culture medium than retained in the scaffold, thus emphasizing the necessity to optimize proteoglycan synthesis and retention by collagen scaffolds (Alini et al., 2003).

Several polysaccharides such as alginate, chitosan and hyaluronic acid have been also explored for chondrocytes encapsulation.

Hyaluronic acid is a major component of the extracellular matrix found in developing embryonic mesenchymal tissues. It can be chemically and physically modified and thus, can be fabricated into a large number of physical forms (Campoccia et al., 1998). Moreover, the chondroinductive properties of the high-molecular-weight form of hyaluronic acid suggest that it can be used as promising material to develop an in vitro model of cartilage (Kujawa and Caplan, 1986; Kujawa et al., 1986). Chemical modifications of this molecule have been introduced to make it highly processable and to modify its grade of biodegradation. The benzylic ester of hyaluronic acid is a biodegradable scaffold, commercially known as Hyaff ${ }^{\circledR}-11$ that is produced in different forms (sponge, non woven, etc.) and has been already used for chondral repair (Aigner et al., 1998; Brun et al., 1999; Grigolo et al., 2001). Recently, Lisignoli and colleagues investigated the in vitro chondrogenic potential of this scaffold culturing human MSCs on Hyaff ${ }^{\circledR}-11$ constructs up to 28 days in the presence of a high concentration of TGF- $\beta$ (20 ng/ $\mathrm{ml}$ ). As shown by the expression profile of genes (such as Sox9, type I, type II, type IX, type X collagens, Aggrecan) expressed at different time during chondrogenesis, the cultures of human MSCs into Hyaff ${ }^{\circledR}-11$ with high concentration of TGF- $\beta$ (20 ng/ml) were characterized by a sequence of cellular and molecular events pointing to the in vitro formation of a cartilage-like tissue (Lisignoli et al., 2005). However, the morphology of the newly-formed tissue was still far from the one of the cartilage that can be obtained by in vivo implantation. In this context, the use of an appropriate mechanical stimulation could be crucial for the development of a functional three-dimensional in vitro cartilage model. Indeed, an enhancement of both type II collagen and aggrecan expression was observed when swine articular chondrocytes were mechanically stimulated for 5 days, thus confirming the importance of considering the mechanical stimuli when designing an ideal cartilage tissue model (Chung et al., 2008).

Alginate is a natural, non-mammalian polysaccharide that forms a gel in the presence of divalent cations by means of ionic crosslinking; it does not degrade, but rather dissolves when the divalent cations are replaced by monovalent ions. Although the alginate scaffolds do not promote cell interaction, Rowley and colleagues have overcome this problem by adding RGD, a cell adhesion peptide, to the scaffolds (Rowley et al., 1999). However, alginate scaffolds without RGD peptides are still commonly used and two studies have recently investigated chondrocyte differentiation in alginate scaffolds (Lin et al., 2008; Xu et al., 2008). Xu and colleagues reported that human MSCs cultured in this type of scaffold showed a time-dependent accumulation of GAG, aggrecan and Type II collagen. Moreover, the authors provided the basis for staging the cellular phenotype into four stages and demonstrated a specific expression pattern of several putative novel marker genes for chondrogenesis (Xu et al., 2008).

An enhancement of chondrocyte differentiation, as confirmed by the synthesis of cartilage-like matrix, was also observed when porcine chondrocytes were seeded in alginate scaffolds and cultured into a perfusion system, thus confirming the potential of alginate scaffolds to promote chondrocyte differentiation (Lin et al., 2008).

Another non-mammalian polysaccharide commonly used to mimic cartilage in vitro is chitosan (Hoemann et al., 2005; Oliveira et al., 2006; Shim et al., 2008). It is made by partially deacetylated chitin; high-degrees of deacetylation lead to slower degradation times but better cell adhesion due to increased hydrophobicity (Mao et al., 2004). The cationic nature of the chitosan hydrogel makes it an attractive scaffold to facilitate the entrapment of the highly anionic aggrecan produced by chondrocytes. Indeed, the majority of proteoglycans produced by human pulposus disc cells cultured in chitosan constructs were retained within the gel rather than released into the culture medium, thus suggesting that chitosan may be a suitable scaffold for cell-base supplementation to help restore the function of the nucleus pulposus (Roughley et al., 2006). Recently, silk fibroin hydrogels were explored for their potential to support chondrogenesis in vitro (Wang Y et al., 2006). Morita and Aoki et al. combined microporous silk fibroin sponges with rabbit chondrocytes for cartilage tissue engineering. The chondrocytes proliferated and maintained the differentiated phenotype in the silk fibroin sponge better than in collagen sponges used as control (Aoki et al., 2003). Moreover, the mechanical properties of the regenerated cartilage tissue showed culture-dependent changes that were directly correlated to the spatial and temporal deposition of cartilage-like ECM (Morita et al., 
2006). Although these studies confirmed the potential of silk hydrogels as 3D porous scaffolds for chondrocytes cultures, further investigations are necessary to obtain a more homogeneous and organized deposition of cartilage-like ECM.

\section{Culturing chondrogenic cells in synthetic-based hydrogels}

Poly(ethylene glycol) (PEG) is the most widely used synthetic polymer to create synthetic-based hydrogels. Although PEG constructs are still considered as potential scaffolds for cartilage regeneration, only a few studies have investigated the in vitro response of chondrocytes cultured into these scaffolds. When encapsulated in a PEG hydrogel with a compressive modulus (i.e., 260-900 kPa) similar to that of human cartilage (i.e. $790 \pm 360 \mathrm{kPa}$ ), chondrocytes remain viable and synthesize cartilage-specific ECM (Bryant and Anseth, 2002; Villanueva et al., 2008). However, the response of the cells cultured within these scaffolds under mechanical stimulation is currently under debate (Bryant et al., 2004; Schmidt et al., 2006). Schmidt and colleagues reported that the dynamic strain stimulation led to a $37 \%$ increase in the levels of GAG after 2 weeks of culture while other studies showed that chondrocytes encapsulated in PEG hydrogels and subjected to dynamic loading conditions for 2 days displayed an inhibition of both proliferation and proteoglycan synthesis. In our opinion, although culture times were different, all results indicate that further studies are required to better understand the effect of PEG environment. The inhibition was greater in PEG hydrogels with higher crosslinking, thus suggesting an important role of the hydrogel structure in the cell response to mechanical stimulations (Nicodemus and Bryant, 2008).

The significance of the hydrogel structure in controlling cell fate has been confirmed by other studies in which nasal chondrocytes were cultured in co-polymeric scaffolds composed of soft, hydrophilic poly(ethylene glycol)-terephthalate (PEGT) and hard, hydrophobic poly(butylenes)-terephtalate (PBT) (Miot et al., 2005). By varying the PEGT MW and the weight percentage ratio between PEGT and PBT, it is possible to modulate the wettability, the protein adsorption, the swelling and the mechanical properties of the substrate. Furthermore, by using diverse fabrication techniques (i.e., compression moulding $(\mathrm{CM})$ or 3D fibre (3DF) deposition), it is possible to obtain scaffolds with the same bulk composition and overall porosity but different inter-connecting pore architectures (Woodfield et al., 2004). Human nasal chondrocytes cultured on high-hydrophilic PEGT/PBT scaffolds synthesized higher amount of GAG and collagen type II compared to the cells seeded on more hydrophobic constructs. Thus, for a given 3D architectures, hydrophilic scaffolds enhanced chondrocytes redifferentiation and cartilage tissue formation (Miot et $a l ., 2005)$. For these reasons, the control of the hydrogel structure is one of the most important research topics on the road to designing an optimal model of functional cartilage tissue.

A novel class of promising biomaterials, composed of spontaneously self-assembling peptides has been recently proposed as molecular engineered scaffolds for tissue engineering (Holmes, 2002). Indeed, some peptides characterized by amino acid sequences of alternating hydrophobic and hydrophilic side groups can self-assemble into stable hydrogels at low peptide concentrations. These self-assembling peptides form stable $\beta$-sheet structures when dissolved in deionised water (Holmes, 2002; Zhang et al., 1993; Zhang et al., 1995). Hydrogel scaffolds based on self-assembling peptides have a nanofibre structure smaller than other polymer microfibres and present a unique polymer structure with which cells may interact. Recently, it has been demonstrated that these types of scaffolds allowed proliferation of different mammalian cell types (Holmes et al., 2000; Kisiday et al., 2002). Kisiday and colleagues reported the use of the self-assembling peptide KLD-12 (based on positively charged lysines, negatively charged aspartic acids and hydrophobic leucines) as a 3D scaffold for encapsulation of bovine chondrocytes (Kisiday et al., 2002). In this study bovine chondrocytes seeded into the scaffolds and cultured in static conditions up to 26 days synthesized and accumulated a cartilage-like ECM. However, total GAG accumulation was similar to that obtained by culturing chondrocytes in other types of polymer and hydrogel scaffolds. It is likely that, also in the case of these self-assembling hydrogels, in order to enhance GAG accumulation and in vitro chondrocyte differentiation, the dynamic mechanical compression of the constructs in association with a low oxygen tension should be implemented in the culture.

\section{Conclusion}

Although the reconstruction of bone segments in vivo is a reality, the development of an in vitro three-dimensional model of bone remains a complex challenge in the field of tissue engineering. In fact, although a large number of different types of scaffolds have been developed and tested for in vitro osteogenic cell cultures, a three-dimensional model that faithfully mimics the bone tissue has not yet been designed and optimized. The major problems concerning the development of in vitro models of bone are the homogeneity of the constructs and the complete differentiation of the osteogenic cells, resulting in tissue that does not resemble the high organization of bone tissue. Although a large number of scaffolds have been tested for in vitro cultures, each one with different chemical composition, we think that the scaffolds need a mineral component that must result osteoinductive and possess mechanical properties similar to functional bone. Until now the main drawbacks of these types of scaffold were due to the opaque nature of this type of biomaterials that did not allow the use of both easy and complex analysis performed with light or fluorescence microscopy. Moreover, the evaluation of the newly formed bone tissue was difficult and the bone could be hardly distinguished from the scaffolds. Whereas in the past the analysis of the cultured scaffolds was difficult to perform and mainly consisted traditional histological methodologies, today the recent development of new techniques such as X-ray microtomography $(\mu \mathrm{CT})$ and X-ray microdiffraction and the combined use of these techniques allow a qualitative and quantitative characterization of the 


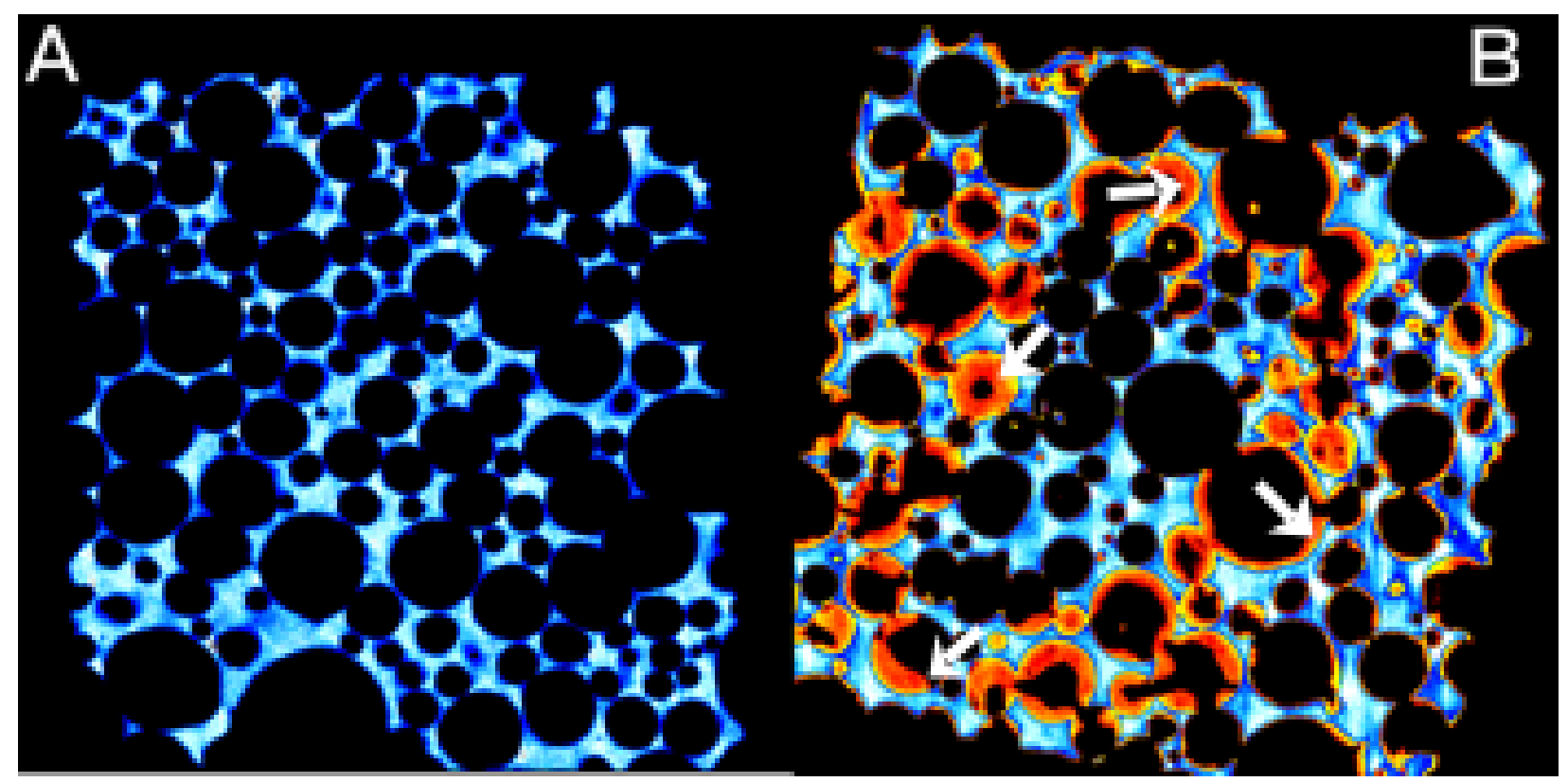

Figure 2: $\mu \mathrm{CT}$ analysis of ceramic scaffolds (A) prior and (B) after the in vivo implantation. The newly-formed bone is highlighted with white arrows. See also Refs. Mastrogiacomo et al. (2007) and Cancedda et al. (2007).

dense scaffold material as well as the $3 \mathrm{D}$ evaluation and kinetic studies of the tissue engineered bone growth within (Fig. 2) (Cancedda et al., 2007; Komlev et al., 2006).

In this context, the development and the optimization of novel bioreactor systems helping the diffusion of nutrient factors through the scaffolds, in combination with an appropriate mechanical stimulation, should assist the in vitro growth of a homogeneous and functional bone-like tissue.

The choice of the scaffold is not the only aspect to take in consideration. Indeed, different cell types should be evaluated (i.e., MSCs, osteoblasts) and tested in order to select the more appropriate for the desired investigation. Although MSCs appear the best choice to study the molecular events that guide osteogenesis, the use of differentiated cells, such as osteoblasts, should be considered to obtain large quantities of extracellular matrix in short-term cultures. Moreover, it is worth noting that bone tissue is not only formed by bone-forming cells and thus, the use of co-cultures appears to be the future in this context. In fact, the optimization of co-culture systems containing both bone- forming and resorbing cells, as well as endothelial cells, will help us to obtain a model that will really mimic the physiological context of the bone environment. In contrast, the development of a good in vitro cartilage model seems an objective that tissue engineering could more rapidly achieve. The micromass culture system described by Johnstone and colleagues and largely used to investigate molecular and cellular cues involved in chondrogenesis as well as to test chondrogenic properties of adult stem cells remains a milestone in cartilage in vitro studies (Johnstone et al., 1998). However, the new challenge in cartilage tissue engineering is the development of larger long-term in vitro constructs. In this context, the use of an appropriate type of scaffold is necessary to obtain an optimal in vitro model of native cartilage. The combination of hydrogels and synthetic polymers could be a good choice to develop functional model of cartilage. Hydrogels ensure a homogeneous colonization of the scaffolds as well as an easy incorporation of growth factors; the synthetic polymers provide the required load-bearing capacity and mechanical integrity.

Possibly, the development of bioreactor systems that will ensure a low perfusion coupled with a low oxygen tension and an appropriate mechanical loading will lead to the development of cartilage tissue models resembling functional natural cartilage.

Finally, we would like to stress that, both in the case of bone and cartilage in vitro models, the choice of scaffold, cells, and protocols should be made also considering that the novel culture system must be cheap, easily available, easy to use and compatible with high-throughput analysis. Indeed, only in this case could the developed models be widely adopted by laboratories, not only for cartilage and bone physiology investigations, but also for tissue specific drug testing.

\section{References}

Aigner J, Tegeler J, Hutzler P, Campoccia D, Pavesio A, Hammer C, Kastenbauer E, Naumann A (1998) Cartilage tissue engineering with novel nonwoven structured biomaterial based on hyaluronic acid benzyl ester. J Biomed Mater Res 42: 172-181.

Alini M., Li W, Markovic P, Aebi M, Spiro RC, Roughley PJ (2003) The potential and limitations of a cell-seeded collagen/hyaluronan scaffold to engineer an intervertebral disc-like matrix. Spine 28: 446-454.

Alvarez-Barreto JF, Shreve MC, Deangelis PL, Sikavitsas VI (2007) Preparation of a functionally flexible, three-dimensional, biomimetic poly(L-lactic acid) scaffold with improved cell adhesion. Tissue Eng 13: 1205-1217. 
Aoki H, Tomita N, Morita Y, Hattori K, Harada Y, Sonobe M, Wakitani S, Tamada Y (2003) Culture of chondrocytes in fibroin-hydrogel sponge. Biomed Mater Eng 13: 309-316.

Bancroft GN, Sikavitsas VI, van den Dolder J, Sheffield TL, Ambrose CG, Jansen JA, Mikos AG (2002) Fluid flow increases mineralized matrix deposition in $3 \mathrm{D}$ perfusion culture of marrow stromal osteoblasts in a dose-dependent manner. Proc Natl Acad Sci U S A 99: 12600-12605.

Barrere F, van Blitterswijk CA, de Groot K (2006) Bone regeneration: molecular and cellular interactions with calcium phosphate ceramics. Int J Nanomedicine 1: 317-320.

Brun P, Abatangelo G, Radice M, Zacchi V, Guidolin D, Daga Gordini D, Cortivo R (1999) Chondrocyte aggregation and reorganization into three-dimensional scaffolds. J Biomed Mater Res 46: 337-346.

Bryant SJ, Anseth KS (2002) Hydrogel properties influence ECM production by chondrocytes photoencapsulated in poly(ethylene glycol) hydrogels. J Biomed Mater Res 59: 63-72.

Bryant SJ, Chowdhury TT, Lee DA, Bader DL, Anseth KS (2004) Crosslinking density influences chondrocyte metabolism in dynamically loaded photocrosslinked poly(ethylene glycol) hydrogels. Ann Biomed Eng 32: 407-417.

Campoccia D, Doherty P, Radice M, Brun P, Abatangelo G, Williams DF (1998) Semisynthetic resorbable materials from hyaluronan esterification. Biomaterials 19: 2101-2127.

Cancedda R., Cedola A, Giuliani A, Komlev V, Lagomarsino S,. Mastrogiacomo M, Peyrin F, Rustichelli F (2007) Bulk and interface investigations of scaffolds and tissue-engineered bones by X-ray microtomography and X-ray microdiffraction. Biomaterials 28: 2505-2524.

Casser-Bette M, Murray AB, Closs EI, Erfle V, Schmidt $\mathrm{J}$ (1990) Bone formation by osteoblast-like cells in a three-dimensional cell culture. Calcif Tissue Int 46: 46-56.

Castano-Izquierdo H, Alvarez-Barreto J, van den Dolder J, Jansen JA, Mikos AG, Sikavitsas VI (2007) Pre-culture period of mesenchymal stem cells in osteogenic media influences their in vivo bone forming potential. J Biomed Mater Res A 82: 129-138.

Causa F, Netti PA, Ambrosio L, Ciapetti G, Baldini N, Pagani S, Martini D, Giunti A (2006) Poly-e-caprolactone/ hydroxyapatite composites for bone regeneration: in vitro characterization and human osteoblast response. J Biomed Mater Res A 76: 151-162.

Charles-Harris M, Koch MA, Navarro Lacroix D, Engel E, Planell JA (2008) A PLA/calcium phosphate degradable composite material for bone tissue engineering: an in vitro study. J Mater Sci Mater Med 19: 1503-1513.

Chen Y, Mak AF, Wang M, Li JS, Wong MS (2008) In vitro behavior of osteoblast-like cells on PLLA films with a biomimetic apatite or apatite/collagen composite coating. J Mater Sci Mater Med 19: 2261-2268.

Chung C, Erickson IE, Mauck RL, Burdick JA (2008) Differential behavior of auricular and articular chondrocytes in hyaluronic acid hydrogels. Tissue Eng Part A 14: 1121-1131.
Ciapetti G, Ambrosio L, Savarino L, Granchi D, Cenni E, Baldini N, Pagani S, Guizzardi S, Causa F, Giunti A (2003) Osteoblast growth and function in porous poly e-caprolactone matrices for bone repair: a preliminary study. Biomaterials 24: 3815-3824.

Cuddihy MJ, Kotov NA(2008) Poly(lactic-co-glycolic acid) bone scaffolds with inverted colloidal crystal geometry. Tissue Eng Part A 14: 1639-1649.

Datta N, Holtorf HL, Sikavitsas VI, Jansen JA, Mikos AG (2005) Effect of bone extracellular matrix synthesized in vitro on the osteoblastic differentiation of marrow stromal cells. Biomaterials 26: 971-977.

Datta N, Pham QP, Sharma U, Sikavitsas VI, Jansen JA, Mikos AG (2006) In vitro generated extracellular matrix and fluid shear stress synergistically enhance 3D osteoblastic differentiation. Proc Natl Acad Sci U S A. 103: 2488-2493.

Dawson JI, Wahl DA, Lanham SA, Kanczler JM, Czernuszka JT, Oreffo RO (2008) Development of specific collagen scaffolds to support the osteogenic and chondrogenic differentiation of human bone marrow stromal cells. Biomaterials 29: 3105-3116.

Domaschke H, Gelinsky M, Burmeister B, Fleig R, Hanke T, Reinstorf A, Pompe W, Rosen-Wolff. A (2006) In vitro ossification and remodeling of mineralized collagen I scaffolds. Tissue Eng 12: 949-958.

Dong J, Uemura T, Shirasaki Y, Tateishi T (2002) Promotion of bone formation using highly pure porous beta-TCP combined with bone marrow-derived osteoprogenitor cells. Biomaterials 23: 4493-4502.

Drury JL, Mooney DJ (2003) Hydrogels for tissue engineering: scaffold design variables and applications. Biomaterials 24: 4337-4351.

Du D, Furukawa K, Ushida T (2008) Oscillatory perfusion seeding and culturing of osteoblast-like cells on porous beta-tricalcium phosphate scaffolds. J Biomed Mater Res A 86: 796-803.

El-Amin SF, Lu HH, Khan Y, Burems J, Mitchell J, Tuan RS, Laurencin CT (2003) Extracellular matrix production by human osteoblasts cultured on biodegradable polymers applicable for tissue engineering. Biomaterials 24: 1213-1221.

Epinette JA, Manley MT (2007) Hydroxyapatite-coated total knee replacement: clinical experience at 10 to 15 years. J Bone Joint Surg Br 89: 34-38.

Eyrich D, Wiese H, Maier G, Skodacek D, Appel B, Sarhan H, Tessmar J, Staudenmaier R, Wenzel MM, Goepferich A, Blunk T (2007) In vitro and in vivo cartilage engineering using a combination of chondrocyte-seeded long-term stable fibrin gels and polycaprolactone-based polyurethane scaffolds. Tissue Eng. 13: 2207-2218.

Ferrera D, Poggi S, Biassoni C, Dickson GR, Astigiano S, Barbieri O, Favre A, Franzi AT, Strangio A, Federici A, Manduca P (2002) Three-dimensional cultures of normal human osteoblasts: proliferation and differentiation potential in vitro and upon ectopic implantation in nude mice. Bone 30: 718-725.

Freed LE, Vunjak-Novakovic G, Biron RJ, Eagles DB, Lesnoy DC, Barlow SK, Langer R (1994) Biodegradable polymer scaffolds for tissue engineering. Biotechnology (N Y) 12: 689-693. 
Fujibayashi S, Neo M, Kim HM, Kokubo T, Nakamura $\mathrm{T}$ (2004) Osteoinduction of porous bioactive titanium metal. Biomaterials 25: 443-450.

Glowacki J, Mizuno S (2008) Collagen scaffolds for tissue engineering. Biopolymers 89: 338-344.

Godbey WT, Atala A (2002) In vitro systems for tissue engineering. Ann N Y Acad Sci 961: 10-26.

Goh YQ, Ooi CP (2008) Fabrication and characterization of porous poly(L-lactide) scaffolds using solid-liquid phase separation. J Mater Sci Mater Med 19: 2445-2452.

Goldstein AS, Zhu G, Morris GE, Meszlenyi RK, Mikos AG (1999) Effect of osteoblastic culture conditions on the structure of poly(DL-lactic-co-glycolic acid) foam scaffolds. Tissue Eng 5: 421-434.

Goldstein AS, Juarez TM, Helmke CD, Gustin MC, Mikos AG (2001) Effect of convection on osteoblastic cell growth and function in biodegradable polymer foam scaffolds. Biomaterials 22: 1279-1288.

Grad S, Kupcsik L, Gorna K, Gogolewski S,Alini M. (2003) The use of biodegradable polyurethane scaffolds for cartilage tissue engineering: potential and limitations. Biomaterials 24: 5163-5171.

Grigolo B, Roseti L, Fiorini M, Fini M, Giavaresi G, Aldini NN, Giardino R, Facchini A (2001) Transplantation of chondrocytes seeded on a hyaluronan derivative (hyaff-11) into cartilage defects in rabbits. Biomaterials 22: 2417-2424.

Gruber HE, Hoelscher GL, Leslie K, Ingram JA, Hanley Jr EN (2006) Three-dimensional culture of human disc cells within agarose or a collagen sponge: assessment of proteoglycan production. Biomaterials 27: 371-376.

Guarino V, Causa F, Taddei P, di Foggia M, Ciapetti G, Martini D, Fagnano C, Baldini N, Ambrosio L (2008) Polylactic acid fibre-reinforced polycaprolactone scaffolds for bone tissue engineering. Biomaterials 29: 3662-3670.

Hannouche D, Terai H, Fuchs JR, Terada S, Zand S, Nasseri BA, Petite H, Sedel L, Vacanti JP (2007) Engineering of implantable cartilaginous structures from bone marrow-derived mesenchymal stem cells. Tissue Eng 13: 87-99.

Hiraoka Y, Kimura Y, Ueda H, Tabata. Y (2003) Fabrication and biocompatibility of collagen sponge reinforced with poly(glycolic acid) fiber. Tissue Eng 9: 1101-1112.

Hoemann CD, Sun J, Legare A, McKee MD, Buschmann MD (2005) Tissue engineering of cartilage using an injectable and adhesive chitosan-based cell-delivery vehicle. Osteoarthritis Cartilage 13: 318-329.

Holmes TC (2002) Novel peptide-based biomaterial scaffolds for tissue engineering. Trends Biotechnol 20:1621.

Holmes TC, de Lacalle S, Su X, Liu G, Rich A, Zhang S (2000) Extensive neurite outgrowth and active synapse formation on self-assembling peptide scaffolds. Proc Natl Acad Sci U S A 97: 6728-6733.

Hosseinkhani H, Inatsugu Y, Hiraoka Y, Inoue S, Tabata Y (2005) Perfusion culture enhances osteogenic differentiation of rat mesenchymal stem cells in collagen sponge reinforced with poly(glycolic acid) fiber. Tissue Eng 11: 1476-1488.

Hutmacher DW (2000) Scaffolds in tissue engineering bone and cartilage. Biomaterials 21: 2529-2543.
Ishaug SL, Crane GM, Miller MJ, Yasko AW, Yaszemski MJ, Mikos AJ. (1997) Bone formation by three-dimensional stromal osteoblast culture in biodegradable polymer scaffolds. J Biomed Mater Res 36: 17-28.

Ishaug-Riley SL, Crane-Kruger GM, Yaszemski MJ, Mikos AG (1998) Three-dimensional culture of rat calvarial osteoblasts in porous biodegradable polymers. Biomaterials 19: 1405-1412.

Johnstone B, Hering TM, Caplan AI, Goldberg VM, Yoo JU (1998) In vitro chondrogenesis of bone marrow-derived mesenchymal progenitor cells. Exp Cell Res 238: 265-272.

Jones AC, Arns CH, Hutmacher DW, Milthorpe BK, Sheppard AP, Knackstedt MA (2009) The correlation of pore morphology, interconnectivity and physical properties of $3 \mathrm{D}$ ceramic scaffolds with bone ingrowth. Biomaterials 30: 1440-1451.

Jung Y, Kim SS, Kim YH, Kim SH, Kim BS, Kim S, Choi CY (2005) A poly(lactic acid)/calcium metaphosphate composite for bone tissue engineering. Biomaterials 26: 6314-6322.

Jung Y, Park MS, Lee JW, Kim YH, Kim SH. (2008) Cartilage regeneration with highly-elastic three-dimensional scaffolds prepared from biodegradable poly(L-lactide-co- $\varepsilon$-caprolactone). Biomaterials 29: 4630-4636.

Karageorgiou V, Kaplan D (2005) Porosity of 3D biomaterial scaffolds and osteogenesis. Biomaterials 26: 5474-5491.

Kisiday J, Jin M, Kurz B, Hung H, Semino C, Zhang S, Grodzinsky AJ (2002) Self-assembling peptide hydrogel fosters chondrocyte extracellular matrix production and cell division: implications for cartilage tissue repair. Proc Natl Acad Sci U S A 99: 9996-10001.

Ko EK, Jeong SI, Rim NG, Lee YM, Shin H, Lee BK (2008) In vitro osteogenic differentiation of human mesenchymal stem cells and in vivo bone formation in composite nanofiber meshes. Tissue Eng Part A 14: 2105-2119.

Komlev VS, Peyrin F, Mastrogiacomo M, Cedola A, Papadimitropoulos A, Rustichelli F, Cancedda R (2006) Kinetics of in vivo bone deposition by bone marrow stromal cells into porous calcium phosphate scaffolds: an $\mathrm{X}$-ray computed microtomography study. Tissue Eng 12: 3449-3458.

Kotobuki N, Ioku K, Kawagoe D, Fujimori H, Goto S, Ohgushi H (2005) Observation of osteogenic differentiation cascade of living mesenchymal stem cells on transparent hydroxyapatite ceramics. Biomaterials 26: 779-785.

Kujawa MJ, Caplan AI (1986) Hyaluronic acid bonded to cell-culture surfaces stimulates chondrogenesis in stage 24 limb mesenchyme cell cultures. Dev Biol 114: 504-518.

Kujawa MJ, Carrino DA, Caplan AI (1986) Substrate-bonded hyaluronic acid exhibits a size-dependent stimulation of chondrogenic differentiation of stage 24 limb mesenchymal cells in culture. Dev Biol 114: 519-528.

Lee CR, Grad S, Gorna K, Gogolewski S, Goessl A, Alini M (2005) Fibrin-polyurethane composites for articular cartilage tissue engineering: a preliminary analysis. Tissue Eng 11: 1562-1573.

Lee YM, Seol YJ, Lim YT, Kim S, Han SB, Rhyu IC, Baek SH, Heo SJ, Choi JY, Klokkevold PR, Chung 
CP (2001) Tissue-engineered growth of bone by marrow cell transplantation using porous calcium metaphosphate matrices. J Biomed Mater Res 54: 216-223.

Leung L, Chan C, Baek S, Naguib H (2008) Comparison of morphology and mechanical properties of PLGA bioscaffolds. Biomed Mater 3: 25006.

Li WJ, Danielson KG, Alexander PG, Tuan RS (2003) Biological response of chondrocytes cultured in three-dimensional nanofibrous poly( $\varepsilon$-caprolactone) scaffolds. J Biomed Mater Res A 67: 1105-1114.

Li WJ, Tuli R, Huang X, Laquerriere P, Tuan RS (2005) Multilineage differentiation of human mesenchymal stem cells in a three-dimensional nanofibrous scaffold. Biomaterials 26: 5158-5166.

Li X, van Blitterswijk CA, Feng Q, Cui F, Watari F (2008) The effect of calcium phosphate microstructure on bone-related cells in vitro. Biomaterials 29: 3306-3316.

Lin YJ, Yen CN, Hu YC, Wu YC, Liao CJ, Chu IM (2008) Chondrocytes culture in three-dimensional porous alginate scaffolds enhanced cell proliferation, matrix synthesis and gene expression. J Biomed Mater Res A 88: 23-33.

Lisignoli G, Cristino S, Piacentini A, Toneguzzi S, Grassi F, Cavallo C, Zini N, Solimando L, Mario Maraldi N, Facchini A (2005) Cellular and molecular events during chondrogenesis of human mesenchymal stromal cells grown in a three-dimensional hyaluronan based scaffold. Biomaterials 26: 5677-5686.

Lutolf MP, Hubbell JA (2005) Synthetic biomaterials as instructive extracellular microenvironments for morphogenesis in tissue engineering. Nat Biotechnol 23: 47-55.

Mackay AM, Beck SC, Murphy JM, Barry FP, Chichester CO, Pittenger MF (1998) Chondrogenic differentiation of cultured human mesenchymal stem cells from marrow. Tissue Eng 4: 415-428.

Mao JS, Cui YL, Wang XH, Sun Y, Yin YJ, Zhao HM, De Yao K (2004) A preliminary study on chitosan and gelatin polyelectrolyte complex cytocompatibility by cell cycle and apoptosis analysis. Biomaterials 25: 3973-3981.

Marcacci M, Kon E, Moukhachev V, Lavroukov A, Kutepov S, Quarto R, Mastrogiacomo M, Cancedda R (2007) Stem cells associated with macroporous bioceramics for long bone repair: 6- to 7-year outcome of a pilot clinical study. Tissue Eng 13: 947-955.

Masi L, Franchi A, Santucci M, Danielli D, Arganini L, Giannone V, Formigli L, Benvenuti S, Tanini A, Beghe F, et al. (1992) Adhesion, growth, and matrix production by osteoblasts on collagen substrata. Calcif Tissue Int 51: 202-212.

Mastrogiacomo M, Cancedda R, Quarto R (2001) Effect of different growth factors on the chondrogenic potential of human bone marrow stromal cells. Osteoarthritis Cartilage 9 Suppl A: S36-40.

Mastrogiacomo M, Corsi A, Francioso E, Di Comite M, Monetti F, Scaglione S, Favia A, Crovace A, Bianco P, Cancedda R (2006a) Reconstruction of extensive long bone defects in sheep using resorbable bioceramics based on silicon stabilized tricalcium phosphate. Tissue Eng 12: 1261-1273.

Mastrogiacomo M, Scaglione S, Martinetti R, Dolcini L, Beltrame F, Cancedda R, Quarto R (2006b) Role of scaffold internal structure on in vivo bone formation in macroporous calcium phosphate bioceramics. Biomaterials 27: 3230-3237.

Mastrogiacomo M, Papadimitropoulos A, Cedola A, Peyrin F, Giannoni P, Pearce SG, Alini M, Giannini C, Guagliardi A, Cancedda R (2007) Engineering of bone using bone marrow stromal cells and a silicon-stabilized tricalcium phosphate bioceramic: evidence for a coupling between bone formation and scaffold resorption. Biomaterials 28: 1376-1784.

Middleton JC, Tipton AJ (2000) Synthetic biodegradable polymers as orthopedic devices. Biomaterials 21: 2335-2346.

Miot S, Woodfield T, Daniels AU, Suetterlin R, Peterschmitt I, Heberer M, van Blitterswijk CA, Riesle J, Martin I (2005) Effects of scaffold composition and architecture on human nasal chondrocyte redifferentiation and cartilaginous matrix deposition. Biomaterials 26: 2479-2489.

Mizuno S, T. Tateishi T, T. Ushida T, and J. Glowacki J (2002) Hydrostatic fluid pressure enhances matrix synthesis and accumulation by bovine chondrocytes in three-dimensional culture. J Cell Physiol 193: 319-327.

Morita Y, Tomita N, Aoki H, Sonobe M, Wakitani S, Tamada Y, Suguro T, Ikeuchi K.(2006) Frictional properties of regenerated cartilage in vitro. J Biomech 39: 103-109.

Mueller SM, Mizuno S, Gerstenfeld LC, Glowacki J (1999) Medium perfusion enhances osteogenesis by murine osteosarcoma cells in three-dimensional collagen sponges. J Bone Miner Res 14: 2118-2126.

Muraglia A, Martin I, Cancedda R, Quarto R (1998) A nude mouse model for human bone formation in unloaded conditions. Bone 22: 131S-134S.

Muraglia A, Corsi A, Riminucci M, Mastrogiacomo M, Cancedda R, Bianco P, Quarto R (2003) Formation of a chondro-osseous rudiment in micromass cultures of human bone-marrow stromal cells. J Cell Sci 116: 2949-2955.

Nam J, Rath B, Knobloch TJ, Lannutti JJ, Agarwal S (2008) Novel electrospun scaffolds for the molecular analysis of chondrocytes under dynamic compression. Tissue Eng Part A 15: 513-523.

Nicodemus GD, Bryant SJ (2008) The role of hydrogel structure and dynamic loading on chondrocyte gene expression and matrix formation. J Biomech 41: 1528-1536.

Oliveira JM, Rodrigues MT, Silva SS, Malafaya PB, Gomes ME, Viegas CA, Dias IR, Azevedo JT, Mano JT, Reis RL (2006) Novel hydroxyapatite/chitosan bilayered scaffold for osteochondral tissue-engineering applications: Scaffold design and its performance when seeded with goat bone marrow stromal cells. Biomaterials 27: 6123-6137.

Ong SM, He L, Thuy Linh NT, Tee YH, Arooz T, Tang G, Tan CH, Yu H (2007) Transient inter-cellular polymeric linker. Biomaterials 28: 3656-3567.

Ong SM, Zhang C, Toh YC, Kim SH, Foo HL, Tan CH, van Noort D, Park S, Yu H (2008) A gel-free 3D microfluidic cell culture system. Biomaterials 29: 3237-3244.

Pham QP, Kurtis Kasper F, Scott Baggett L, Raphael RM, Jansen JA, Mikos AG (2008) The influence of an in vitro generated bone-like extracellular matrix on osteoblastic gene expression of marrow stromal cells. Biomaterials 29: $2729-2739$. 
Pietak AM, Reid JW, Stott MJ, Sayer M (2007) Silicon substitution in the calcium phosphate bioceramics. Biomaterials 28: 4023-4032.

Porter JR, Henson A, Popat KC (2009) Biodegradable poly ( $\varepsilon$-caprolactone) nanowires for bone tissue engineering applications. Biomaterials 30: 780-788.

Quarto R, Mastrogiacomo M, Cancedda R, Kutepov SM, Mukhachev V, Lavroukov A, Kon E, Marcacci M (2001) Repair of large bone defects with the use of autologous bone marrow stromal cells. N Engl J Med 344 385-386.

Quinn TM, Grodzinsky AJ, Buschmann MD, Kim YJ, Hunziker EB (1998) Mechanical compression alters proteoglycan deposition and matrix deformation around individual cells in cartilage explants. J Cell Sci 111: 573583.

Rezwan K, Chen QZ, Blaker JJ, Boccaccini AR (2006) Biodegradable and bioactive porous polymer/inorganic composite scaffolds for bone tissue engineering. Biomaterials 27: 3413-3431.

Robins JC, Akeno N, Mukherjee A, Dalal RR, Aronow BJ, Koopman P, Clemens TL (2005) Hypoxia induces chondrocyte-specific gene expression in mesenchymal cells in association with transcriptional activation of Sox9. Bone 37: 313-322.

Roughley P, Hoemann C, DesRosiers E, Mwale F, Antoniou J, Alini M (2006) The potential of chitosan-based gels containing intervertebral disc cells for nucleus pulposus supplementation. Biomaterials 27: 388-396.

Rowley JA, Madlambayan G, Mooney DJ (1999) Alginate hydrogels as synthetic extracellular matrix materials. Biomaterials 20: 45-53.

Saini S, Wick TM (2004) Effect of low oxygen tension on tissue-engineered cartilage construct development in the concentric cylinder bioreactor. Tissue Eng 10: 825-832.

Schmidt O, Mizrahi J, Elisseeff J, Seliktar D (2006) Immobilized fibrinogen in PEG hydrogels does not improve chondrocyte-mediated matrix deposition in response to mechanical stimulation. Biotechnol Bioeng 95: 1061-1069.

Sekiya I, Colter DC, Prockop DJ (2001) BMP-6 enhances chondrogenesis in a subpopulation of human marrow stromal cells. Biochem Biophys Res Commun 284: 411-418.

Sekiya I, Vuoristo JT, Larson BL, Prockop DJ (2002) In vitro cartilage formation by human adult stem cells from bone marrow stroma defines the sequence of cellular and molecular events during chondrogenesis. Proc Natl Acad Sci U S A. 99: 4397-4402.

Shim IK, Suh WH, Lee SY, Lee SH, Heo SJ, Lee MC, Lee SJ (2008) Chitosan nano-/microfibrous double-layered membrane with rolled-up three-dimensional structures for chondrocyte cultivation. J Biomed Mater Res A 90: 595602 .

Sikavitsas VI, Bancroft GN, Holtorf HL, Jansen JA, Mikos AG (2003) Mineralized matrix deposition by marrow stromal osteoblasts in $3 \mathrm{D}$ perfusion culture increases with increasing fluid shear forces. Proc Natl Acad Sci U S A 100: 14683-14688.

Spoerke ED, Stupp SI (2003) Colonization of organoapatite-titanium mesh by preosteoblastic cells. J Biomed Mater Res A 67: 960-969.
Stiehler M, Bunger C, Baatrup A, Lind M, Kassem M, Mygind T (2009) Effect of dynamic 3-D culture on proliferation, distribution, and osteogenic differentiation of human mesenchymal stem cells. J Biomed Mater Res A 89: 96-107.

Storrie H, Stupp SI (2005) Cellular response to zinc-containing organoapatite: an in vitro study of proliferation, alkaline phosphatase activity and biomineralization. Biomaterials 26: 5492-5499.

Stupp SI, Ciegler GW (1992) Organoapatites: materials for artificial bone. I. Synthesis and microstructure. J Biomed Mater Res 26: 169-183.

Stupp SI, Hanson JA, Eurell JA, Ciegler GW, Johnson A (1993a). Organoapatites: materials for artificial bone. III. Biological testing. J Biomed Mater Res 27: 301-311.

Stupp SI, Mejicano GC, Hanson JA (1993b) Organoapatites: materials for artificial bone. II. Hardening reactions and properties. J Biomed Mater Res 27: 289-299.

Sung HJ, Meredith C, Johnson C, Galis ZS (2004) The effect of scaffold degradation rate on three-dimensional cell growth and angiogenesis. Biomaterials 25: 5735-5742.

Timmins NE, Scherberich A, Fruh JA, Heberer M, Martin I, Jakob M (2007) Three-dimensional cell culture and tissue engineering in a T-CUP (tissue culture under perfusion). Tissue Eng 13: 2021-2028.

Tsuji H (2005) Poly(lactide) stereocomplexes: formation, structure, properties, degradation, and applications. Macromol Biosci 5: 569-597.

Uemura T, Dong J, Wang Y, Kojima H, Saito T, Iejima D, Kikuchi M, Tanaka J, Tateishi T (2003) Transplantation of cultured bone cells using combinations of scaffolds and culture techniques. Biomaterials 24: 2277-2286.

van den Dolder J, Bancroft GN, Sikavitsas VI, Spauwen PH, Jansen JA, Mikos AG (2003) Flow perfusion culture of marrow stromal osteoblasts in titanium fiber mesh. J Biomed Mater Res A 64: 235-241.

Verrier S, Blaker JJ, Maquet V, Hench LL, Boccaccini AR (2004) PDLLA/Bioglass composites for soft-tissue and hard-tissue engineering: an in vitro cell biology assessment. Biomaterials 25: 3013-3021.

Villanueva I, Hauschulz DS, Mejic D, Bryant SJ (2008) Static and dynamic compressive strains influence nitric oxide production and chondrocyte bioactivity when encapsulated in PEG hydrogels of different crosslinking densities. Osteoarthritis Cartilage 16: 909-918.

Wahl DA, Czernuszka JT (2006) Collagen-hydroxyapatite composites for hard tissue repair. Eur Cell Mater 11: 43-56.

Wang J, Asou A, Sekiya I, Sotome S, Orii O, Shinomiya K (2006) Enhancement of tissue engineered bone formation by a low pressure system improving cell seeding and medium perfusion into a porous scaffold. Biomaterials 27: 2738-2746.

Wang S, Cui W, Bei J (2005) Bulk and surface modifications of polylactide. Anal Bioanal Chem 381: 547-556.

Wang Y, Kim HJ, Vunjak-Novakovic G, Kaplan DL (2006) Stem cell-based tissue engineering with silk biomaterials. Biomaterials 27: 6064-6082.

Wendt D, Riboldi SA, Cioffi M, Martin I (2009) Bioreactors in tissue engineering: Scientific challenges and 
clinical perspectives. Adv Biochem Eng Biotechnol 112: $1-27$.

Wernike E, Li Z, Alini M, Grad S (2008) Effect of reduced oxygen tension and long-term mechanical stimulation on chondrocyte-polymer constructs. Cell Tissue Res 331: 473-483.

Woodfield TB, Malda J, de Wijn J, Peters F, Riesle J, van Blitterswijk CA (2004) Design of porous scaffolds for cartilage tissue engineering using a three-dimensional fiber-deposition technique. Biomaterials 25: 4149-4161.

Xie J, Han Z, Kim SH, Kim YH, Matsuda T (2007) Mechanical loading-dependence of mRNA expressions of extracellular matrices of chondrocytes inoculated into elastomeric microporous poly(L-lactide-co- $\varepsilon$-caprolactone) scaffold. Tissue Eng 13: 29-40.

Xu J, Wang W, Ludeman M, Cheng K, Hayami T, Lotz JC, Kapila S (2008) Chondrogenic differentiation of human mesenchymal stem cells in three-dimensional alginate gels. Tissue Eng Part A 14: 667-680.

Yamaguchi M, Oishi H, Suketa Y (1987) Stimulatory effect of zinc on bone formation in tissue culture. Biochem Pharmacol 36: 4007-4012.

Yao J, Radin S, Leboy PS, Ducheyne P (2005) The effect of bioactive glass content on synthesis and bioactivity of composite poly (lactic-co-glycolic acid)/bioactive glass substrate for tissue engineering. Biomaterials 26: $1935-$ 1943.

Yoshikawa T, Ohgushi H, Tamai S (1996) Immediate bone forming capability of prefabricated osteogenic hydroxyapatite. J Biomed Mater Res 32: 481-492.

Yu X, Botchwey ED, Levine EM, Pollack SR, Laurencin CT (2004) Bioreactor-based bone tissue engineering: the influence of dynamic flow on osteoblast phenotypic expression and matrix mineralization. Proc Natl Acad Sci U S A 101: 11203-11208.

Zhang S, Holmes T, Lockshin C, Rich A (1993) Spontaneous assembly of a self-complementary oligopeptide to form a stable macroscopic membrane. Proc Natl Acad Sci U S A 90: 3334-3338.
Zhang S, Holmes TC, DiPersio CM, Hynes RO, Su X, Rich A (1995) Self-complementary oligopeptide matrices support mammalian cell attachment. Biomaterials 16: 1385-1393.

Zwingmann J, Mehlhorn AT, Sudkamp N, Stark B, Dauner M, Schmal H (2007) Chondrogenic differentiation of human articular chondrocytes differs in biodegradable PGA/PLA scaffolds. Tissue Eng 13: 2335-2343.

\section{Discussion with Reviewers}

Reviewer I: In the context of three-dimensional cultures of osteogenic and chondrogenic cells and the development of bone and cartilage tissues the study of endochondral ossification is of particular interest. Can the authors comment on an ideal model system to investigate this process in vitro? Authors: An ideal model of endochondral ossification should resume all the molecular and cellular features that drive the cartilage to bone transition. MSC should undergo an initial chondrogenic differentiation and subsequently be induced to differentiate to osteoblastic cells. In this context, the choice of the culture medium plays a key role on the road to obtain a functional in vitro model. The cells should be initially maintained in a chondrogenic medium and then switched to an osteogenic medium. Muraglia et al. (1998) reported the formation of a bony-collar around cartilage pellets by using this strategy. However, the scaffold-free constructs obtained in this way had several limitations such as the poor mechanical strength and the small dimension of newly-formed tissue. The use of scaffolds that permit the development of soft cartilage and the deposition of bone-like matrix during the osteogenic-phase of the culture could overcome these drawbacks. In our opinion, hydrogel/ bioceramics composites are the preferred choice. Indeed, the hydrogel should ensure the homogeneity of the cultures and chondrogenic differentiation, while the presence of the mineral should favour osteoblastic differentiation. 